\title{
Large scale variation in Enterococcus faecalis illustrated by the genome analysis of strain OG IRF
}

Agathe Bourgogne $^{* \dagger}$, Danielle A Garsin ${ }^{\ddagger}$, Xiang Qin§, Kavindra V Singh ${ }^{* \dagger}$, Jouko Sillanpaa** , Shailaja Yerrapragada§, Yan Ding§, Shannon DuganRocha§, Christian Buhay§, Hua Shen§, Guan Chen§, Gabrielle Williams ${ }^{\S}$, Donna Muzny§, Arash Maadani ${ }^{\ddagger}$, Kristina A Fox ${ }^{\ddagger}$, Jason Gioia§, Lei Chen§, Yue Shang§, Cesar A Arias ${ }^{* \dagger}$, Sreedhar R Nallapareddy ${ }^{* \dagger}$, Meng Zhao ${ }^{* \dagger}$, Vittal P Prakash ${ }^{* \dagger}$, Shahreen Chowdhury ${ }^{* \dagger}$, Huaiyang Jiang§, Richard A Gibbs ${ }^{\S \uparrow}$, Barbara E Murray ${ }^{* \neq}$, Sarah K Highlander§¥ and George M Weinstock $\$$ $₫$

\begin{abstract}
Addresses: ${ }^{*}$ Division of Infectious Diseases, Department of Medicine, University of Texas Medical School, Houston, Texas 77030 , USA. ${ }^{\dagger}$ Center for the Study of Emerging and Re-emerging Pathogens, University of Texas Medical School, Houston, Texas 77030, USA. ${ }^{*}$ Department of Microbiology and Molecular Genetics, University of Texas Medical School, Houston, Texas 77030, USA. §Human Genome Sequencing Center, Baylor College of Medicine, Houston, Texas 77030, USA. "Department of Molecular and Human Genetics, Baylor College of Medicine, Houston, Texas 77030, USA. ${ }^{¥}$ Department of Molecular Virology and Microbiology, Baylor College of Medicine, Houston, Texas 77030, USA.
\end{abstract}

Correspondence: Barbara E Murray. Email: Barbara.E.Murray@uth.tmc.edu

Published: 8 July 2008

Genome Biology 2008, 9:RI 10 (doi:I0.I I86/gb-2008-9-7-rII0)

The electronic version of this article is the complete one and can be found online at http://genomebiology.com/2008/9/7/RII0
Received: 14 February 2008

Revised: 8 May 2008

Accepted: 8 July 2008

(C) 2008 Bourgogne et al.; licensee BioMed Central Ltd.

This is an open access article distributed under the terms of the Creative Commons Attribution License (http://creativecommons.org/licenses/by/2.0), which permits unrestricted use, distribution, and reproduction in any medium, provided the original work is properly cited.

\begin{abstract}
Background: Enterococcus faecalis has emerged as a major hospital pathogen. To explore its diversity, we sequenced $E$. faecalis strain OGIRF, which is commonly used for molecular manipulation and virulence studies.

Results: The 2,739,625 base pair chromosome of OGIRF was found to contain approximately 232 kilobases unique to this strain compared to V583, the only publicly available sequenced strain. Almost no mobile genetic elements were found in OGIRF. The 64 areas of divergence were classified into three categories. First, OGIRF carries 39 unique regions, including 2 CRISPR loci and a new WxL locus. Second, we found nine replacements where a sequence specific to V583 was substituted by a sequence specific to OGIRF. For example, the iol operon of OGIRF replaces a possible prophage and the vanB transposon in V583. Finally, we found 16 regions that were present in V583 but missing from OGIRF, including the proposed pathogenicity island, several probable prophages, and the cpsCDEFGHIJK capsular polysaccharide operon. OGIRF was more rapidly but less frequently lethal than V583 in the mouse peritonitis model and considerably outcompeted V583 in a murine model of urinary tract infections.
\end{abstract}

Conclusion: $E$. faecalis OGIRF carries a number of unique loci compared to V583, but the almost complete lack of mobile genetic elements demonstrates that this is not a defining feature of the species. Additionally, OGIRF's effects in experimental models suggest that mediators of virulence may be diverse between different $E$. faecalis strains and that virulence is not dependent on the presence of mobile genetic elements. 


\section{Background}

Enterococci have emerged over the past few decades as the second to third most common cause of nosocomial infections, including urinary tract and soft tissue infections, bacteremia, and endocarditis [1-3]. They are well equipped to thrive in environments with heavy antibiotic usage due to both their intrinsic resistance to antibiotics and their talent for swapping genetic information, which allows them to gain and share resistance determinants. Entecococcal infections are predominantly caused by E. faecalis and E. faecium. However, many, if not most, strains of these species are harmless commensals, with some enterococci being marketed in Europe to alleviate symptoms of irritable bowel syndrome and recurrent chronic sinusitis or bronchitis (Cylactin ${ }^{\circledR}$ and Fargo688 ${ }^{\circledR}$ (E. faecium) and Symbioflor 1 (E. faecalis)). To differentiate the two faces of this organism, genome-wide comparisons are necessary. Although hundreds of microbial genomes have been sequenced, only two E. faecalis genomes have been reported (V583 as a clinical isolate [4] and Symbioflor 1 as a commensal isolate [5]), but only the V583 genome has been made publicly available. In this strain, more than one-quarter of the genome is mobile DNA, more than any other sequenced bacterial genome [4]. The occurrence of multiple antibiotic resistance determinants in V583 [6] makes it difficult to manipulate genetically. Moreover, the vancomycin resistance phenotype makes this strain more of a risk to handle in the laboratory. To avoid these issues, most laboratories use strain OG1 or its close derivatives. OG1 is a human isolate subsequently shown to cause dental caries in rats [7]. OG1RF is a rifampicin and fusidic acid resistant derivative of OG1 $[8,9]$. By pulsed-field gel electrophoresis, Murray et al. [10] estimated the size of the OG1RF genome as $2,825 \mathrm{~kb}$ and created a restriction map of the chromosome. Multilocus sequence typing (MLST) showed that OG1RF is clonally distinct from V583 (differs in six out of seven alleles of housekeeping genes) [11] and characterization of regions flanking transposon insertions in OG1RF suggested that approximately $10 \%$ of their sequences differed [12].

OG1 and its derivatives have been successfully used over the past 20 years in various animal models, starting with the demonstration that it can cause caries in germ-free rats [7], and later to characterize factors important for $E$. faecalis virulence in a mouse model of peritonitis [13], a rabbit model of endophthalmitis [14], a rat model of endocarditis [15] and in a mouse urinary tract infection model [16]. OG1RF was also shown to be as virulent as $\mathrm{V}_{5} 83$ in the model host Caenorhabditis elegans [17]. In addition to its virulence, the main reasons for the extensive use of $\mathrm{OG} 1 \mathrm{RF}$ as a laboratory strain are that it does not carry plasmids, is readily transformable by electroporation, and is not resistant to commonly used antibiotics, other than rifampicin and fusidic acid. These resistances were serially selected in OG1 to provide strain markers [9]. The lack of resistance to common antibiotics facilitates the selection of plasmids, transposons, and allelic replacement markers introduced into the strain.
Numerous factors important for virulence have been characterized in OG1RF. A recently described example are the Ebp pili, whose subunits are encoded by the ebp operon [18] and whose genes are regulated by EbpR [19]. A non-piliated mutant produces less biofilm than the parent strain and is attenuated in a rat model of endocarditis [18] and in a murine urinary tract infection model [16]. Also present is Ace, a member of the MSCRAMM (microbial surface component recognizing adhesive matrix molecules) family. The ace gene, like the $e b p$ locus, is ubiquitous in E. faecalis and it occurs in at least four different forms that vary in the number of repeats of the B domain [20]. Ace mediates conditional (that is, after growth at $46^{\circ} \mathrm{C}$ or in the presence of serum or collagen) adherence of $E$. faecalis to collagen type IV and to laminin [21] and, in unpublished data, influences the ability of OG1RF to cause experimental endocarditis (KV Singh and BE Murray, unpublished observation). Finally, the Fsr system, a major positive and negative transcriptional regulator in OG1RF [22], affects expression of several virulence factor genes, including gelE, which encodes gelatinase [23], and contributes to infection in various animal models $[15,24]$.

The distinct MLST profile and the wide range of phenotypic and genotypic analyses of OG1RF, including many molecular genetic studies and experiments in various animal models, suggested that genomic analysis of this strain would prove insightful and would be useful to future studies. Thus, we analyzed the sequence of $E$. faecalis $\mathrm{OG} 1 \mathrm{RF}$. This revealed approximately $232 \mathrm{~kb}$ encoding 227 open reading frames (ORFs) that are unique to this important strain compared to $\mathrm{V} 583$. The unique regions were then characterized further.

\section{Results and discussion \\ General genome features}

The complete circular chromosome of OG1RF was found to be $2,739,625$ bp with an average $\mathrm{G}+\mathrm{C}$ content of $37.8 \%$. The complete OG1RF sequence was obtained using three independent techniques (Solexa, the 454, and Sanger sequencing technique) with a higher than classic coverage (more than 100 times), diminishing the likelihood of sequencing-related frameshifts, base errors and/or misassembly. A comparison of our assembly of the closed OG1RF genome with the restriction map of OG1RF published by Murray et al. [10] showed only minor variations (primarily an overestimation of $30 \mathrm{~kb}$ for the $S f i$ I fragment E, $540 \mathrm{~kb}$ versus $509 \mathrm{~kb}$ predicted from the sequence; Figure 1).

We found $232 \mathrm{~kb}$ of $\mathrm{OG} 1 \mathrm{RF}$ unique sequences distributed in 48 regions ranging from $101 \mathrm{bp}$ to approximately $49 \mathrm{~kb}$ in length (Figure 1; Additional data file 1). Using the published DNA sequence of V583 as reference (NC_o04668), OG1RF shares 2,474 ORFs as well as the 12 rRNA genes and 58 of 68 tRNA genes (Table 1 ). The 10 missing tRNA are localized in a region in $\mathrm{V}_{5} 83$ that has been replaced in $\mathrm{OG}_{1} \mathrm{RF}$ by a $49 \mathrm{~kb}$ region (see below). Surprisingly, the genomes align synteni- 


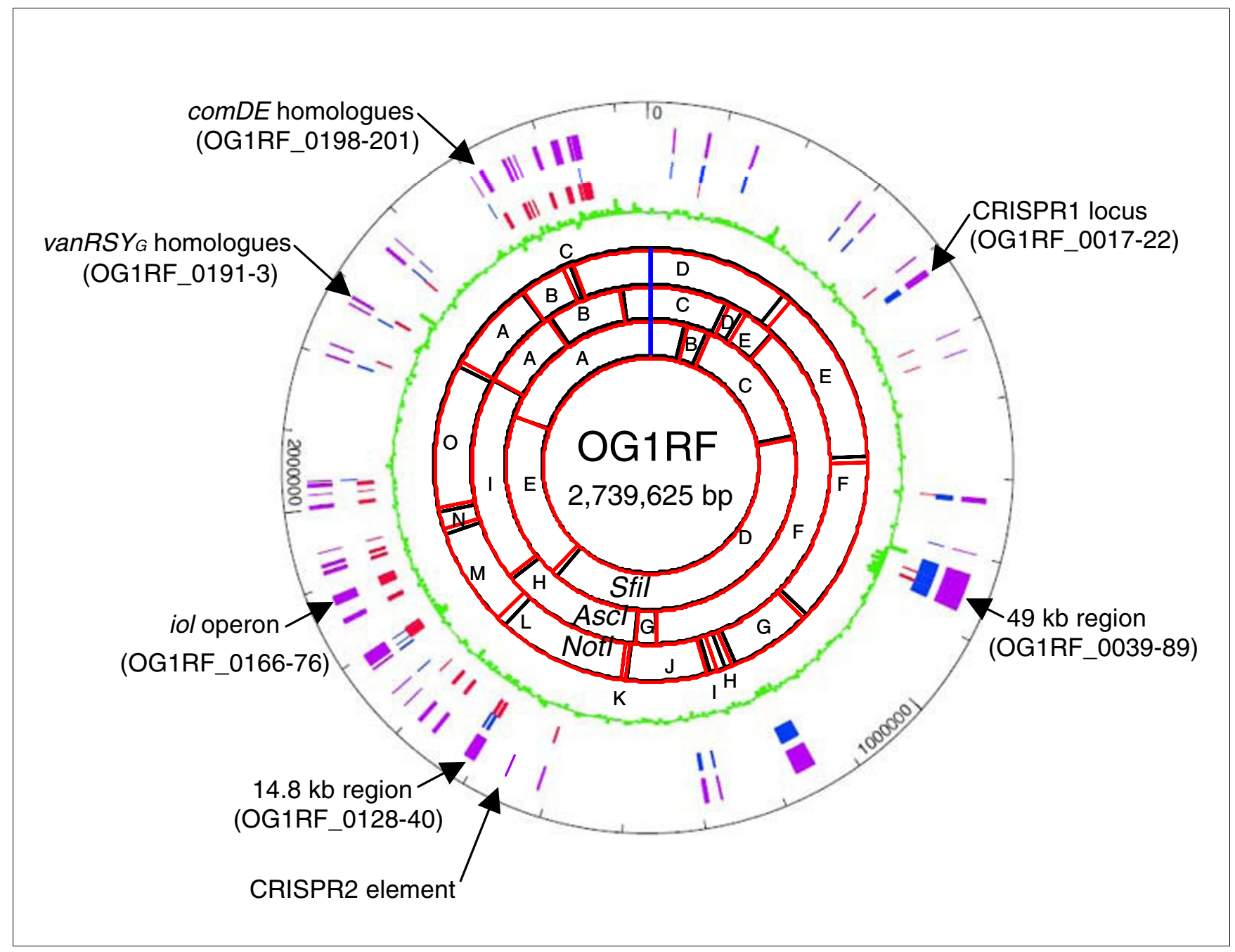

Figure I

Map of the OGIRF chromosome. The following features are displayed (from the inside out): restriction maps using Sfil, Ascl, and Notl (black) from Murray et al. [10] overlaid with the digestion profile predicted from the sequence (red); G+C content in percentage in green; the total OGIRF-unique genes are shown in purple with those in $(+)$ orientation labeled in blue, and those in $(-)$ orientation labeled in red.

cally, as shown in Figure 2, despite the fact that 25\% of the V583 genome is composed of mobile elements. Similarly, the presence of OG1RF-unique sequences has not affected the overall chromosomal arrangement. Some of the major insertions/deletions in the two genomes are shown in Figure 2, such as the absence of the pathogenicity island (PAI) in OG1RF and the presence of an approximately $49 \mathrm{~kb}$ fragment unique to OG1RF. However, most of the differences are small and cannot be visualized in this figure. Overall, we found 64 areas of divergence between the genomes that can be divided into 3 classes: an additional sequence present in OG1RF when compared with V583; a sequence replacement where a sequence in OG1RF differs from the sequence in V583; and the absence of a sequence from OG1RF when compared with $\mathrm{V}_{5} 83$.

\section{CRISPR loci}

The CRISPR (comprised of regularly interspaced short palindromic repeats) loci encoded by some bacterial strains is a recently described system that protects cells from infection with bacteriophage [25-27]. The specificity of the phage resistance conferred by the CRISPR elements and CRISPRassociated genes (cas genes) is determined by spacer-phage sequence similarity. OG1RF carries two CRISPR elements: CRISPR1 (between the OG1RF homologue of EFo672 and EFo673) and CRISPR2 (between the OG1RF homologue of EF2062 and EF2063); CRISPR1 is linked to cas-like genes while CRISPR2 is not (Figure 3). Both OG1RF CRISPR elements are composed of 7 repeats of a $37 \mathrm{bp}$ palindromic sequence with a 29 bp spacer. None of the 29 bp spacers (14 total) have homology to any sequences in GenBank. The CRISPR1-associated proteins belong to the Nmeni subtype [28]. Species bearing this CRISPR/cas subtype have so far been found exclusively in bacteria that are vertebrate patho- 
Table I

\begin{tabular}{|c|c|c|c|}
\hline & V583 & & OGIRF \\
\hline \multicolumn{4}{|l|}{ General features } \\
\hline Size (base pairs) & $3,218,031$ & & $2,739,633$ \\
\hline $\mathrm{G}+\mathrm{C}$ content $(\%)$ & 37.5 & & 37.8 \\
\hline rRNA genes & 12 & & 12 \\
\hline tRNA genes & 68 & & 58 \\
\hline Genes common to both strains & & $2,474^{*}$ & \\
\hline \multicolumn{4}{|l|}{ Genes unique to OGIRF } \\
\hline Similar to known proteins & & & $114 \dagger$ \\
\hline Conserved hypotheticals & & & 50 \\
\hline No database match & & & 63 \\
\hline Total & & & 227 \\
\hline Total number of ORFs & 3,113 & & $2,701 \ddagger$ \\
\hline
\end{tabular}

*The assessment of the genes common to both strains is based on the homology at the DNA level with the ORFs described for V583 (source TIGR [70]). The BLASTN cutoff e-value was Ie-5. tThis number includes the proteins with domain polymorphism (see text for details). \#Estimated number of ORFs calculated by adding the OGIRF-unique ORFs to the number of ORFs shared with V583.

gens or commensals. The Nmeni subtype is characterized by the presence of four specific cas genes and a single copy of the repeat that is upstream of the first gene in the locus. The four cas genes encode Cas_csn1 (possible endonuclease), Cas1 (novel nuclease), Cas2 (conserved hypothetical protein), and Cas_csn2 (conserved hypothetical protein). The repeat upstream of cas_csn1 appears to have degenerated since it shares only $23 \mathrm{bp}$ with the $37 \mathrm{bp}$ repeat cluster downstream of the last gene. A unique feature of the OG1RF CRISPR1 locus is the presence of a gene downstream of the element, which encodes a hypothetical 119 amino acid transmembrane protein.

The presence of the CRISPR loci among E. faecalis strains may be a powerful tool to avoid the load of prophage replication. To determine the distribution of the CRISPR1 locus in $E$. faecalis strains, 16 isolates of various MLST types were tested for the presence (PCR with primers specific for csn1 and cas1) or absence (PCR with primers overlapping the junction between EFo672 and EFo673) of the CRISPR1 locus (Table 2). Seven strains were cas positive, but negative for the junction and the remaining nine were positive only for the junction. This indicates that the location of the CRISPR1 locus appears to be conserved (between EFo672 and EFo673 when compared with the $V_{5} 83$ genome). Interestingly, the two vancomycin resistant strains tested were both cas negative. It is appealing to postulate that the presence of the CRISPR locus in OG1RF may be the reason for the absence of prophage in this strain.

\section{A $14.8 \mathrm{~kb}$ region inserted in the $\mathbf{2 3 . 9} \mathrm{kb}$ region containing fsrA and $f s r B$}

Nakayama et al. [29] described a conserved $23.9 \mathrm{~kb}$ chromosomal deletion when comparing $f s r A$-lacking $/ f s r C^{+} / g e l E^{+}$ strains (by PCR) from various origins with $\mathrm{V}_{5} 83$; the deleted sequences start in the middle of $\mathrm{EF} 1841$, include the $f_{s r} A B$ genes and end in the middle of the $f_{s r C}$ gene (EF1820). Loss of the $f s r$ regulatory components results in a gelatinase-negative phenotype under routine test conditions despite the fact that these strains still carry the gelE gene $[23,29]$. The absence/presence of the $23.9 \mathrm{~kb}$ region, from $\mathrm{EF} 182 \mathrm{O} / \mathrm{fsrC}$ to EF1841, did not appear to correlate with the clinical origin of the isolates [30]. In a more recent analysis of relationships between various $E$. faecalis strains, the $23.9 \mathrm{~kb}$ region was not detected in $86 \%$ of the strains of the clonal complex (CC)2, $58 \%$ of the CC9 strains, nor in any of the CC8 strains [31]. The Symbioflor 1 strain, used as a probiotic, is one representative of the $7.4 \%$ of $E$. faecalis isolates that are missing the gelE gene in addition to the $23.9 \mathrm{~kb}$ region [5,30]. Our analysis of this area in OG1RF revealed the presence of an additional 14.8 $\mathrm{kb}$ fragment inserted between the corresponding EF1826 and EF1827 of OG1RF (confirmed by PCR; results not shown). In OG1RF, this $14.8 \mathrm{~kb}$ region contains two loci, a WxL locus (described below) and a seven-gene locus that may encode a possible $\mathrm{ABC}$ transporter with similarity to one annotated in Pediococcus pentosaceus.

\section{Components of the cell surface}

It has been shown in E. faecalis that at least one cell surface protein (Ace) is subject to domain variation [20] and it has been postulated that domain variation may help bacteria escape the immune system. We found more polymorphisms in two families of $E$. faecalis proteins present on the cell surface: the MSCRAMMs and the WxL domain surface proteins. The MSCRAMMs are composed of two large regions, namely, the non-repeat A region (which is usually the ligand binding region for extracellular matrix molecules such as collagen or fibrinogen) and the $B$ region (which typically contains repeated sub-domains). The $\mathrm{B}$ region of Ace contains five repeats in OG1RF, while it contains only four in V583 [20]. We found two other MSCRAMM proteins that show polymorphisms in the number of their B repeats. OG1RF_0186 (corresponding to $\mathrm{EF}_{25} 5 \mathrm{O}$ of $\mathrm{V}_{5} 83$ ) has four repeats compared to seven in V583, and OG1RF_0165 (corresponding to EF2224 of V583) has eight repeats compared to five in V583. It has been proposed that the repeats are used as a stalk that projects the A region across the peptidoglycan and away from the cell surface [32]. A hypothesis that the number of repeats may be proportional to the depth of the peptidoglycan has been proposed [32]. However, OG1RF_0186 carries fewer repeats than EF2505 while Ace and OG1RF_0165 carry more repeats than their counterparts in $V_{5} 83$, suggesting that our 


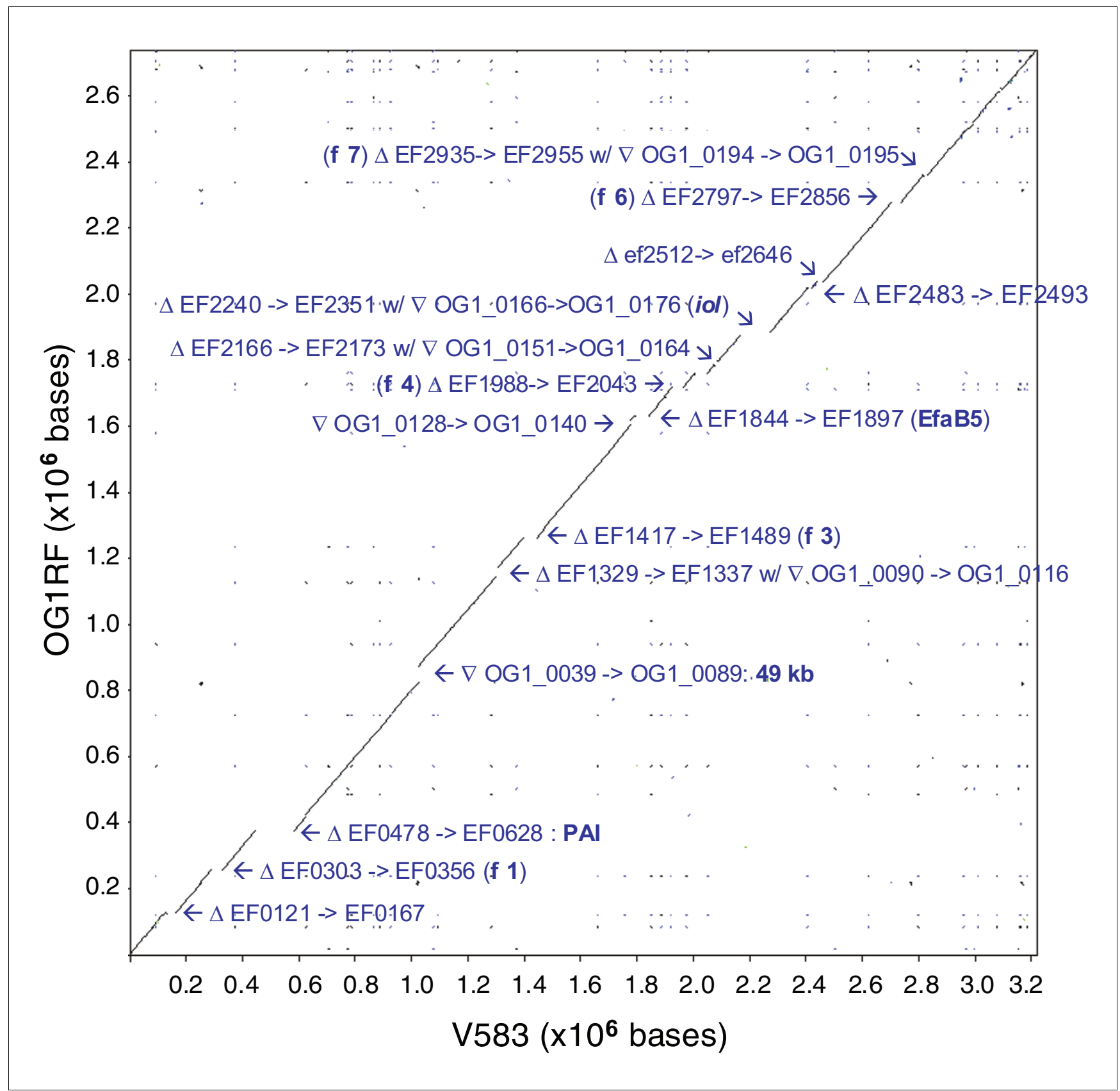

Figure 2

Dot plot of OGIRF versus V583 generated by BLASTN. The dot plot was generated by aligning the ORIRF genome against the V583 genome using BLASTN (e-value le-10). The alignment pairs were plotted according to their genome coordinates. The visible areas of divergences are labeled using ' $\Delta$ ' to indicate a sequence absent in OGIRF and ' $\nabla$ ' to indicate a sequence unique to OGIRF (locus tag OGI_xxxx) when compared with V583 (locus tag EFxxxx). Phages I, 3, 4, 5, 6, 7 of V583 ( $\phi I$ to 7; see [3I]) and the PAI locations, all of which are missing from OGIRF, are also indicated.

observation does not fit this hypothesis or that the peptidoglycan depth is not uniform. Apart from these three MSCRAMMs with B-repeat polymorphisms, we identified two unique MSCRAMM proteins in OG1RF: a homologue of EFoo89 (OG1RF_0063, which shares 48\% similarity) and a homologue of EF1896 (OG1RF_0039, which shares 75\% similarity); both are located in the approximately $49 \mathrm{~kb}$ region unique to OG1RF described below (Figure 1; Additional data file 1).

Another family of $E$. faecalis surface proteins includes the newly described WxL domain surface proteins. Siezen et al. [33] reported a novel gene cluster encoding exclusively cellsurface proteins that is conserved in a subgroup of Gram-positive bacteria. Each gene cluster has at least one member of 
(a)

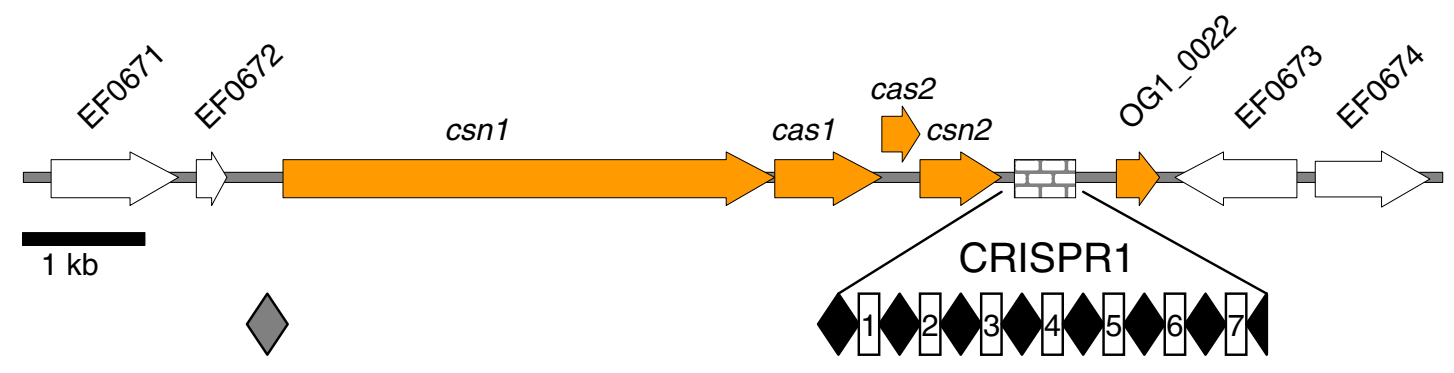

(b)

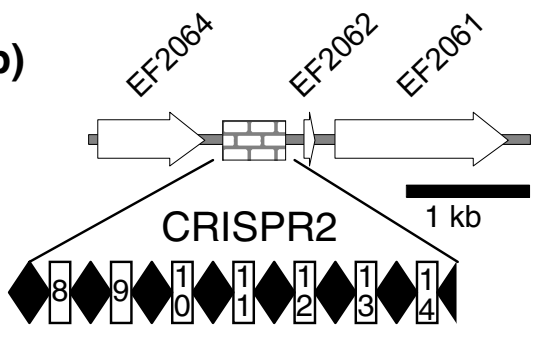

(c)

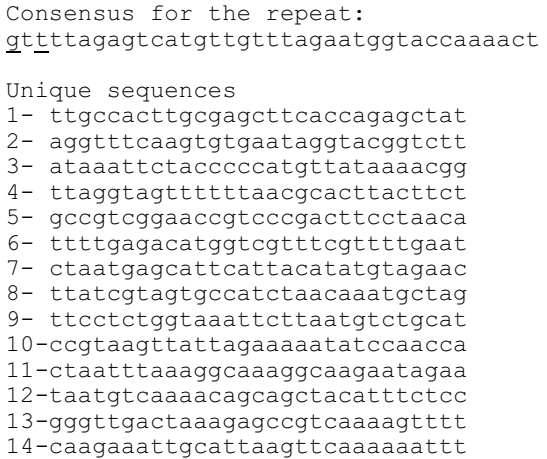

Figure 3

The two CRISPR loci of OGIRF. (a) The CRISPRI locus. The CRISPRI element is represented with a hatched box while the CRISPRI associated genes are represented in orange; the white arrows indicate ORFs present in both OGIRF and V583. The black diamonds represent the 37 bp repeat sequences, while the open boxes with a number indicate the 29 bp unique sequences. (b) The CRISPR2 locus containing only a CRISPR element. (c) CRISPR consensus and unique sequences. The underlined bases indicate mismatches at these locations. The sequences numbered I to I 4 represent the unique sequences located in the CRISPRI and CRISPR2 elements.

three gene families: a gene encoding a small LPxTG protein (approximately 120 amino acids); a gene encoding a member of the DUF916 transmembrane protein family; and a gene encoding a WxL domain surface protein. In addition, members of these gene families were found as singletons or associated with genes encoding other proteins (Additional data file 2). Recently, it was shown that the WxL domain attaches to the peptidoglycan on the cell surface [34] and one member of this WxL domain family, the homologue of EF2686 in OG1RF (a probable internalin protein), was shown to be important for virulence in a mouse peritonitis model and is required for dissemination to the spleen and liver [35]. OG1RF shares five complete WxL loci with V583 (EFo750-7, EF2682-6, EF2970-68, EF3181-8, and EF3248-53). OG1RF does not contain homologues of EF2248-54 (carrying instead the iol operon), though it has a novel WxL locus within the $14.8 \mathrm{~kb}$ unique region upstream of the $f s r$ locus (Additional data file 2). In addition to the variation in the number of WxL loci, we also observed polymorphisms in six of the WxL domain surface proteins. For example, OG1RF_0213 shares 88\% similarity with EF3188, while OG1RF_o224, OG1RF_0225, and OG1RF_0227 share $64-68 \%$ similarity with their V583 coun- terparts, EF3248, EF3250, and EF3252, respectively. Also, in place of EF3153, EF3154, and EF3155 (which share 70\% similarity among themselves), were found non-distantly related homologues, OG1RF_0209 and OG1RF_0210, which share $60-80 \%$ similarity with EF3153, EF3154, and EF3155. It is interesting to note that while several of these WxL loci, including the EFO750 and EF3184 loci, were present by hybridization in all the strains (clinical or food isolates) tested by Lepage et al. [36], other loci, including the EF3153 and EF3248 loci, were not detected in the majority of these strains. In addition, it appears that the EF3248 locus diverges in the Symbioflor 1 strain. When compared to $\mathrm{V}_{583}$, the sequence identity in this area between the two strains appears to be as low as $75 \%$ (depicted in Figure 2 from reference [5]).

However, because the Symbioflor 1 genome sequence is not currently available, it was not possible to compare their respective sequences in more detail. Since these proteins are located at the surface of the cell, the low level of homology shared between them may be the result of antigenic variation. More analyses are required for a better understanding of the number, frequency and function of these WxL domain pro- 
Table 2

\begin{tabular}{|c|c|c|c|c|c|c|c|c|}
\hline Name & Other & Origin & Source/reference & MLST & ErmR* & VanRt & cas $\ddagger$ & EF0672-3§ \\
\hline TX4002 & OGIRF & Human & {$[8,9]$} & 1 & - & - & + & - \\
\hline TX2708 & V583 & Clinical isolate & [6] & $6 \pi$ & + & + & - & + \\
\hline $\mathrm{TX} 2 \mid 44$ & EI840 & Clinical isolate & Ruiz-Garbajosa P.\# & 40 & + & - & + & - \\
\hline $\mathrm{TX} 2135$ & EI795 & Hospital survey & Ruiz-Garbajosa P. & 44 & - & - & - & + \\
\hline $\mathrm{T} \times 2137$ & EI798 & Hospital survey & Ruiz-Garbajosa P. & 16 & + & - & + & - \\
\hline$T \times 2|4|$ & $\mathrm{E} 1825$ & Clinical isolate & Ruiz-Garbajosa P. & 25 & - & - & - & + \\
\hline$T \times 2140$ & $\mathrm{E} 1803$ & Hospital survey & Ruiz-Garbajosa P. & 38 & - & - & - & + \\
\hline $\mathrm{TX} 2138$ & $\mathrm{E} I 80 \mathrm{I}$ & Hospital survey & Ruiz-Garbajosa P. & 48 & - & - & - & + \\
\hline $\mathrm{TX} 2146$ & EI844 & Clinical isolate & Ruiz-Garbajosa P. & 61 & - & - & - & + \\
\hline$T \times 2139$ & $\mathrm{E} 1802$ & Hospital survey & Ruiz-Garbajosa P. & 35 & + & - & + & - \\
\hline TX4240 & A0826 & Pig & Jensen L. & 98 & + & - & + & - \\
\hline TX4247 & El876 & Pig & Gaastra W. & 20 & + & - & + & - \\
\hline TX4245 & El872 & Dog & Gaastra W. & 16 & + & - & + & - \\
\hline TX4243 & E0252 & Calf & Mevius D. & 23 & + & + & - & + \\
\hline TX4255 & A0808 & Clinical isolate & Kawalec M. & 88 & - & - & - & + \\
\hline TX4259 & Al006 & Clinical isolate & Kawalec M. & 135 & - & - & - & + \\
\hline
\end{tabular}

*Erythromycin resistance was tested at $5 \mu \mathrm{g} / \mathrm{ml}$. †Vancomycin resistance was tested at $10 \mu \mathrm{g} / \mathrm{ml}$. 抽o sets of primers were used to detect the cas genes (cas I and csn I). \$This set of primers amplifies the junction between EF0672 and EF0673 where the CRISPRI locus is inserted in OGIRF. TCC2. \# Ruiz-Garbajosa P. (Spain), Jensen L. (Denmark), Gaastra W. and Mevius D. (Netherland), and Kawalec M. (Poland).

teins and their possible relationship with the diversity of $E$. faecalis.

Finally, as previously found using PCR, the cpsCDEFGHIJK operon capsule polysaccharide genes [37] were confirmed here as missing, although OG1RF carries the $c p s A$ and $c p s B$ genes, which were proposed to be essential for $E$. faecalis since all strains tested by Hufnagel et al. [37] carry these two genes. In $\mathrm{OG} 1 \mathrm{RF}$, the region that would encode the cps operon is only $59 \mathrm{bp}$ in length and has no homology with V583. Thus, while V583 and OG1RF share much similarity between their surface components, there are unique differences that could potentially be important in affecting the behavior of the strains and might be useful for strain typing.

\section{Two-component regulatory systems}

OG1RF lacks four two-component systems found in V583. These are histidine kinase-response regulator (HK-RR)o8, HK-RR12 located in the PAI, HK-RR16 and the vanB regulatory system HK-RR11 [38]. However, an OG1RF-unique twocomponent system with high homology with the van $_{\mathrm{G}}$ locus was found at the location corresponding to the region between EF2860 and EF2861 in V583 (Table 3). OG1RF_0193 shares 82\% similarity with $\operatorname{VanR}_{\mathrm{G}}$ and $81 \%$ similarity with $\operatorname{VanR}_{\mathrm{G} 2}$. Similarly, OG1RF_0192 shares $68 \%$ similarity with $\operatorname{VanS}_{\mathrm{G}}$ and $\operatorname{VanS}_{\mathrm{G} 2}$. A gene (OG1RF_0191) encoding an M15 family muramoyl pentapeptide carboxypeptidase is located downstream of these two-component regulatory genes (Figure 4a). The predicted carboxypeptidase (OG1RF_0191) shares 69\% similarity over 179 amino acids with EF2297, a membrane-associated D, D-carboxypeptidase encoded by the vanB operon in V583. However, OG1RF_0191 lacks an identifiable transmembrane domain that is important to the VanY function and it is likely, therefore, that this protein may be a soluble D, D-carboxypeptidase/transpeptidase as seen in Streptomyces [39] and Actinomadura [40], and thus may not be involved in peptidoglycan metabolism. Consequently, it seems unlikely that this operon is a remnant of a vancomycin resistance operon in OG1RF, but rather part of a still unknown regulatory pathway.

\section{The iol operon}

OG1RF carries an iol operon while V583 does not. This operon encodes the factors necessary for the degradation of myo-inositol into glyceraldehyde-3P. Many soil and plant micro-organisms, including Bacillus subtilis [41] (first iol operon identified), Klebsiella spp. [42], and cryptococci [43], have been reported to use myo-inositol as a sole carbon source. Myo-inositol, one of the nine isomers of the inositol group, belongs to the cyclitol group and is abundant in nature, particularly in the soil. The OG1RF iol operon appears to be closely related to ones described in Clostridium perfringens [44] and Lactobacillus casei [45]. In L. casei, the myoinositol operon consists of ten genes with an upstream divergent regulator gene, iolR. In OG1RF, the operon appears to include ten genes, beginning with a probable transcriptional regulator (helix-turn-helix domain protein). Also, the OG1RF operon carries two copies of an iolG-like gene, which encodes inositol 2-dehydrogenase, the first enzyme of the myo-inositol degradation pathway (Figure 5). However, the order of the genes is not the same between E. faecalis and L. casei. In addition, iolH,iolJ and iolK, present in L. casei, are not 
Table 3

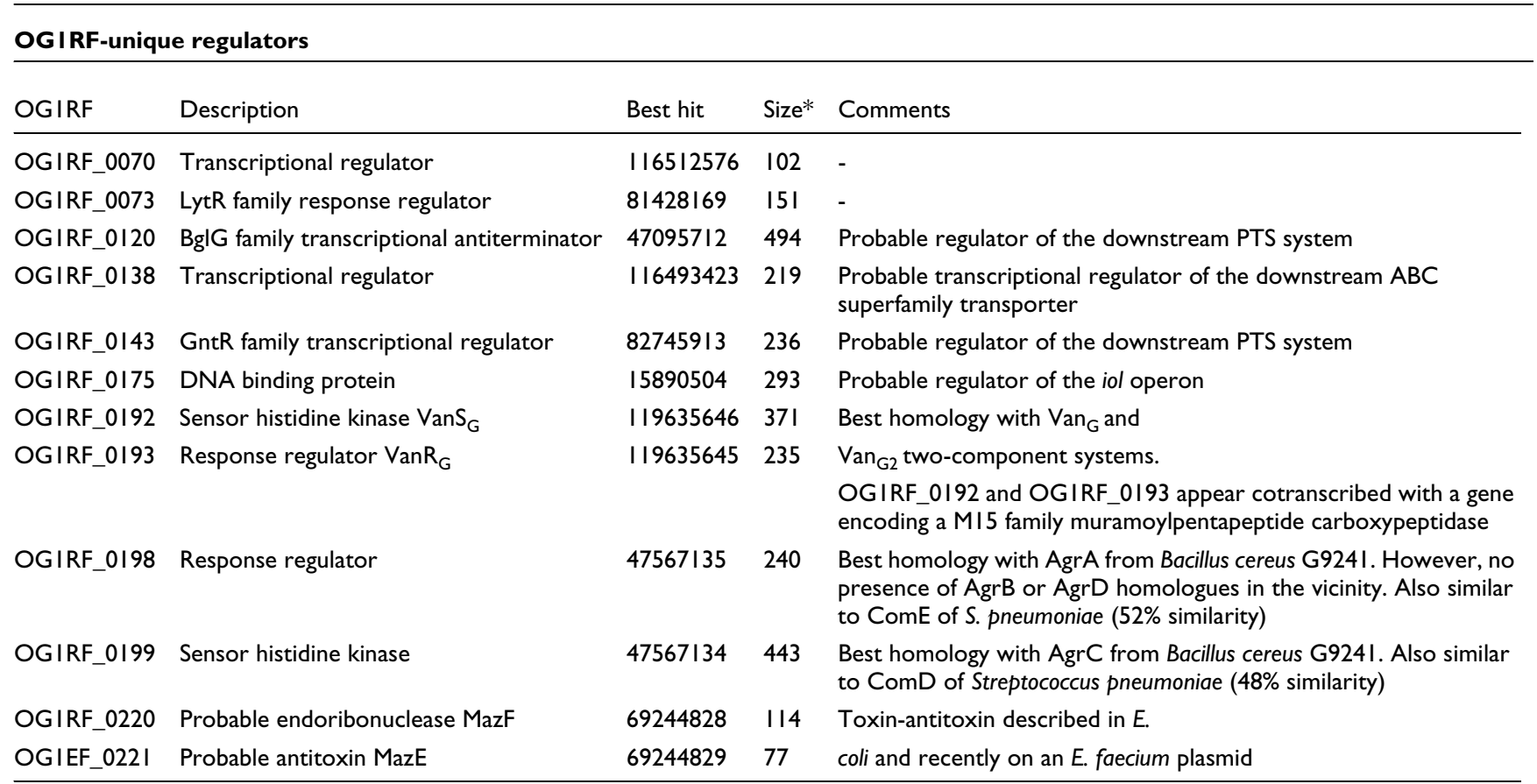

*Amino acids

present in OG1RF, nor are iolH and iolK present in the C. perfringens iol operon.

Yebra et al. reported that $L$. casei was the sole member of the Lactobacillales to carry a functional iol operon [45]. To survey
E. faecalis, also a member of this order, for the presence of the iol operon, 48 isolates with different MLST and/or from various origins (including OG1RF and $\mathrm{V}_{583}$ ) were tested for

(a)

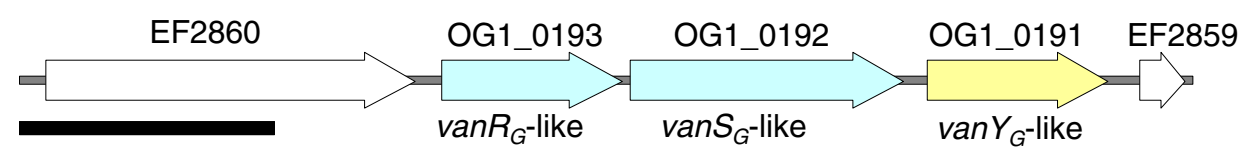

$1 \mathrm{~kb}$

(b)

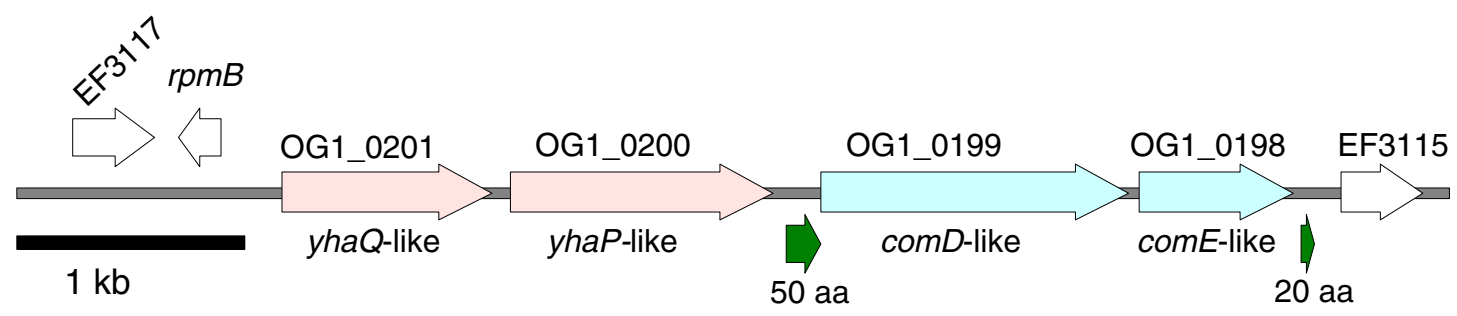

\section{Figure 4}

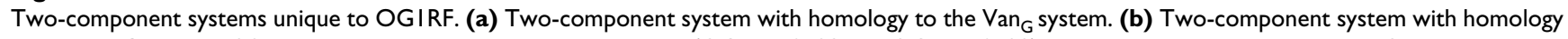
to the comCD genes of $S$. pneumoniae. The two-component system (OGIRF_0I98 and OGIRF_0199) is indicated in light blue; the two ORFs encoding potential transporter proteins (OGIRF_0200 and OGIRF_020I) are represented in pink. In green are indicated two small ORFs encoding polypeptides of less than $5 \mathrm{I}$ amino acids. The white arrows indicate ORFs also present in V583. 


\section{Enterococcus faecalis OG1RF}

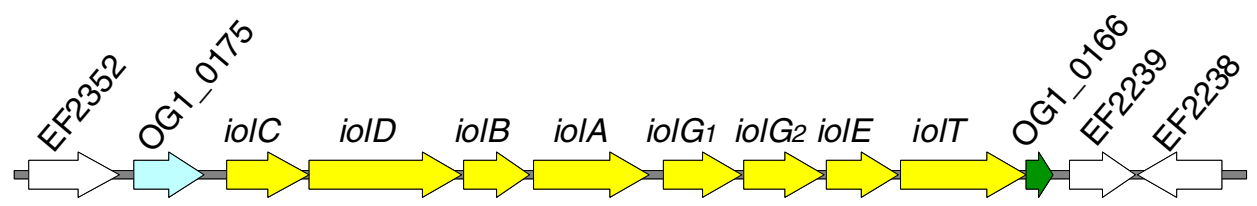

\section{Bacillus subtilis 168}

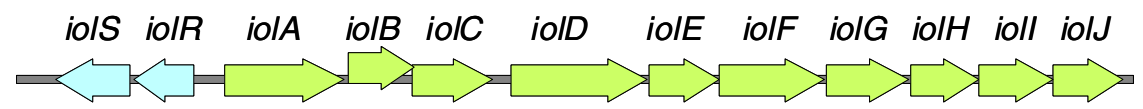

\section{Clostridium perfringens 13}

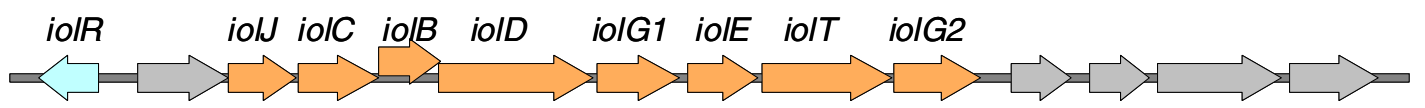

\section{Lactobacillus casei BL23}

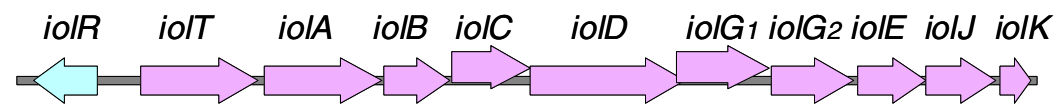

\section{Figure 5}

The iol operon. The iol genes are labeled based on the homology/conserved motif of their encoded proteins with known enzymes necessary for myoinositol degradation. For all strains, the described or probable regulator is represented in blue. E. faecalis OG IRF: the iol operon is represented in yellow, OGIRF_0166 (green arrow) located downstream of the iol operon encodes a probable PTS IIC component, while the white arrows indicate ORFs also present in V583. For B. subtilis 168 , C. perfringens strain I3, and L. casei BL23, the iol genes are represented in green, orange and purple, respectively. $C$. perfringens iol mRNA transcript includes five other genes encoding proteins whose functions do not appear to be related to myo-inositol degradation; these genes are represented in gray.

myo-inositol fermentation; 23 of 48 isolates were positive. In addition, PCR verified the presence of iolE and iolR in these strains and in one negative for myo-inositol fermentation, indicating that the iol operon is not unique to OG1RF. To verify that the iol genes are responsible for the fermentation of myo-inositol in OG1RF, transposon insertion mutants [9] in the iolB and iolG2 genes of OG1RF were tested. Both mutants failed to ferment myo-inositol (data not shown), demonstrating that these genes are essential for myo-inositol fermentation. To investigate whether the iol operon was 'inserted into' or 'removed from' a putative ancestral strain, the sequences surrounding the iol genes were examined. In OG1RF, the iol operon is located between the equivalent of EF2239 and EF2352 when compared with V583. In V583, this region encodes probable prophage proteins and carries the vanB transposon, which confers vancomycin resistance. Since we did not identify any remnants of the iol operon in V583, it would appear that at least two independent events at the same location differentiate OG1RF and $V_{5} 83$, suggesting that it is a hot region for rearrangement. This region between
EF2239 and EF2352 (111 Kb) is also missing in the Symbioflor 1 strain (referred to as gap 2) [5]. The possible junction and presence of unique sequence in this region, if investigated, was not mentioned in the publication. Nonetheless, preliminary analysis of other strains' genotypes in this area seemed to confirm the hypothesis of a hot region for rearrangement (data not shown).

\section{A homologue of Tn916 in OG IRF}

An analysis of the $\mathrm{G}+\mathrm{C}$ content of $\mathrm{OG} 1 \mathrm{RF}$ unique regions revealed several loci with a lower $\mathrm{G}+\mathrm{C}$ content than the $37.8 \%$ average content of OG1RF. One of these is an approximately $49 \mathrm{~kb}$ fragment with a $\mathrm{G}+\mathrm{C}$ content of $32.1 \%$ located between an rRNA operon and the homologue in OG1RF of EF1053, replacing 10 tRNA genes present in V583 (Figure 1). This fragment appears to be a patchwork composed of hypothetical genes, homologues of Tn916-associated genes and homologues of genes from other Gram-positive organisms, including Listeria, E. faecium, staphylococci, or lactococci (Additional data file 1). It is interesting to note that this region 
contains: a putative adhesin protein gene (OG1RF_oo39) at one end of the fragment; homologues of 14 Tn916-associated genes (Tn916_2 to Tn916_12, Tn916_18 and Tn916_19, with an average of $70 \%$ similarity); and a gene encoding a putative integrase (OG1RF_oo88) at the other end - these three features are also present in Tn5386 in E. faecium D344R [46]. However, the approximately $49 \mathrm{~kb}$ fragment lacks an excisase gene and the probable lantibiotic $\mathrm{ABC}$ transporter genes present in $\operatorname{Tn} 5386$.

\section{An uninterrupted competence operon in OG IRF}

OG1RF contains what appears to be an intact competence operon while that of $\mathrm{V}_{5} 83$ appears to be non-functional. This operon in OG1RF is similar to a nine-gene operon described in Streptococcus mutans [47], as shown in Figure 6. For example, the homologue in OG1RF of EF2046 shares $61 \%$ similarity with ComYA and the OG1RF homologue of EF2045 is $55 \%$ similar to ComYB. In $S$. mutans, only the first seven genes of the operon are essential for competence [47]. In $\mathrm{V} 583$, the fourth gene of this operon (corresponding to OG1RF_0148) is interrupted by phage 4 (EF1896-EF2043); in addition, EF1984 contains a premature stop codon not found in the corresponding gene in OG1RF (OG1RF_o228).

Natural competence has not been reported for E. faecalis. To assess the functionality of this operon in OG1RF, we evaluated the competence of cells in different phases of growth (early log growth to stationary phase) using pAM401 [48] and pMSP3535VA [49]. We were not able to show natural competence under the conditions tested. We have also noted that
$\mathrm{V}_{5} 83$ is less transformable by electroporation than OG1RF. To investigate the possibility that directly or indirectly the com operon might be responsible for this phenotype, we also evaluated transformability by electroporation. When compared with OG1RF, transposon mutants [12] in the OG1RF equivalent of EF2045 (encoding the comGB homologue) and in the OG1RF equivalent of EF1986 (encoding the comGF homologue) showed similar levels of transformability by electroporation (data not shown), implying that the difference in electroporation efficiency observed between OG1RF and $\mathrm{V} 583$ is not related to this locus.

In Streptococcus pneumoniae [50], the competence operon is tightly regulated by a quorum sensing two-component system (ComDE) and a competence-stimulating peptide (CSP; encoded by comC). We did not find any homologues of CSP in OG1RF. Two homologous ComDE sensor histidine kinase/ response regulators were found in $\mathrm{OG} 1 \mathrm{RF}$, one of which is FsrC/FsrA. Based on our previous microarray data, the Fsr system does not regulate the com $Y$ operon, at least under our previously used conditions (mid-log phase growth to early stationary phase in brain heart infusion (BHI)) [22]. The other ComDE homology is that with a two-component system unique to OG1RF (OG1RF_0199 and OG1RF_0198, respectively) that lies on a $4,706 \mathrm{bp}$ unique fragment that maps between EF3114 and EF3115 in V583. This fragment also carries two genes (OG1RF_o20o and OG1RF_0201) encoding homologues of the YhaQ and YhaP sodium efflux ATP-binding cassette efflux/transporter proteins (Figure 4b). Although they are potential elements of a secretion apparatus, these

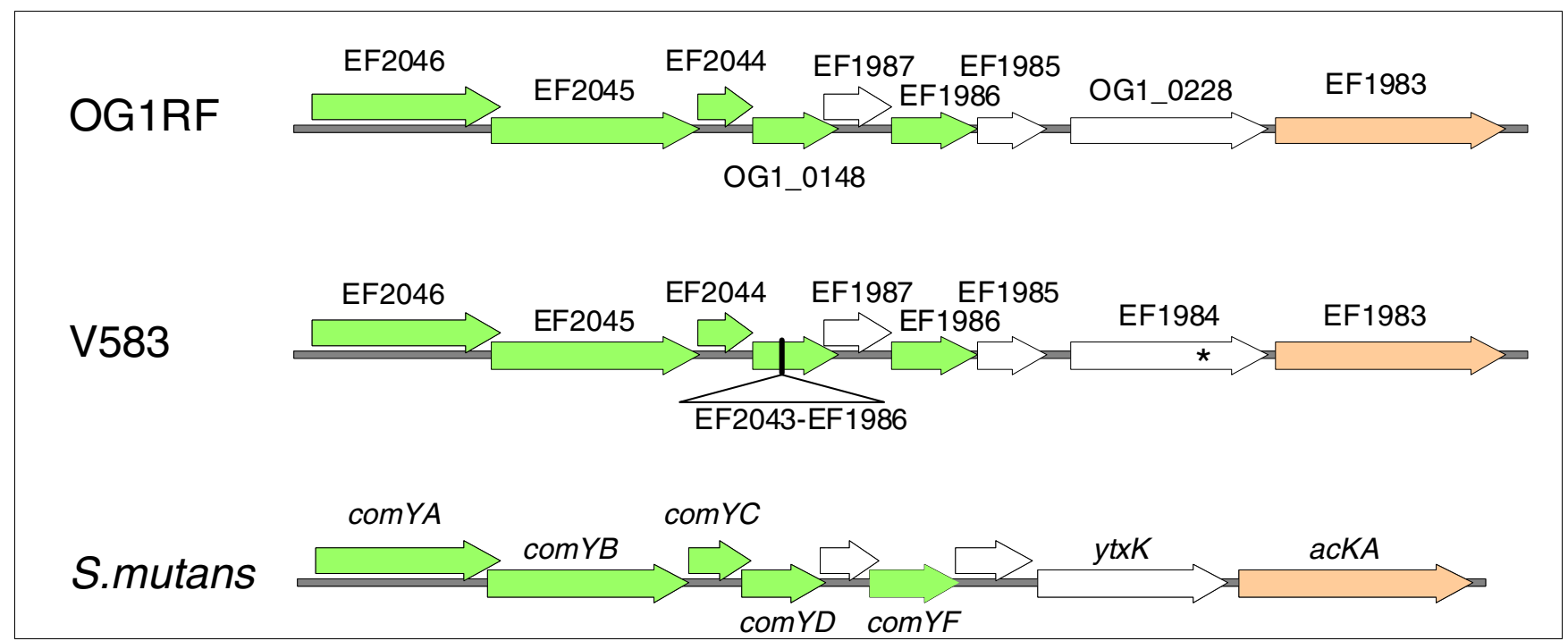

Figure 6

The OGIRF competence operon and its similarity with the competence operon of S. mutans. The ORFs essential for natural competence in S. mutans are shown in green as well as their homologues in OGIRF and V583. The ORF corresponding to the homologue of ComYD was not described in V583 [4], due to the presence of a probable prophage (EFI986-EF2043). The premature stop codon in EFI 984 in V583 is indicated with an asterisk. ackA/EFI983 is represented in orange. The proteins encoded by the ORFs represented in white do not share any features of the known competence proteins or homology between S. mutans and E. faecalis; in S. mutans, ackA and ytxK are co-transcribed with the com $Y$ genes [47]. 
two proteins do not share any homology at the protein level with the competence secretion apparatus ComAB of $S$. pneumoniae [51] nor CslAB from S. mutans [52]. Searching for a possible CSP in the vicinity of these genes, we identified a small ORF encoding 50 amino acids between yhaP and OG1RF199 and another encoding 20 amino acids downstream of OG1RF198. More analysis will be required to determine if there are conditions in which the OG1RF com operon is expressed and to determine whether or not this two-component system is involved in competence.

\section{Limited presence of mobile elements}

By probing a microarray of the $\mathrm{V}_{5} 83$ genome and plasmids with OG1RF genomic DNA, we previously estimated that only $75 \%$ of $\mathrm{V}_{5} 83$ ORFs were also present in $\mathrm{OG}_{1 \mathrm{RF}}$ [22]. Later, Aakra et al. [53] compared nine strains, including OG1RF to $\mathrm{V} 583$, using comparative genomic hybridization. In these results, OG1RF appears to carry a few genes included in the PAI, and a few prophage genes. Using the complete genome sequence, we have now found that OG1RF lacks 639 genes and the three pTET plasmids described in V583. All but 45 of the missing genes are associated with putative mobile elements, such as the entire PAI, the recently described phages $1,3,4,5,6$, and 7 [31], and the approximately $111 \mathrm{~kb}$ area between genes EF2240 and EF2351 (including the vanB transposon) present in $\mathrm{V}_{583}$. The absence of these elements appears also to be a characteristic of the commensal strain Symbioflor 1, although because the genome was not completely finished, the possibility remains that some of these regions were not sequenced. In conclusion, other than the approximately $49 \mathrm{~kb}$ fragment containing a Tn916 homologue, it appears that OG1RF has only one additional possible mobile element derivative, namely the phage 2 proposed to be part of the core genome [31].

\section{Fusidic acid and rifampicin resistance}

OG1RF was sequentially selected from OG1 for resistance to fusidic acid and rifampicin [9]. The mutation leading to rifampicin resistance was identified in the $r p o B$ gene by Ozawa et al. [54] and is caused by the A1467G mutation, which results in substitution of arginine for histidine at amino acid 489. The mutation also affected the clumping phenotype of traA mutants and this effect appears to be specific for the pAM373 system [54]. All of the other 22 differences in rpoB between OG1RF and V583 are synonymous. Fusidic acid resistance is associated with mutation(s) in the fus $A$ gene, which encodes elongation factor G. We compared fusA from OG1RF with that in $\mathrm{V}_{5} 83$ and identified two differences (C1368A and T1992C). The mutation T1992C is synonymous, while the mutation $\mathrm{C} 1368 \mathrm{~A}$ leads to the presence of glutamine (histidine in V583) at position 404 in OG1RF. Mutations in this region have been associated with fusidic acid resistance in Staphylococcus aureus [55,56], and thus the C1368A mutation is likely the cause of the fusidic acid resistance phenotype in OG1RF.

\section{Virulence and biofilm comparisons of OG IRF with V583}

When compared in the mouse peritonitis model, the $\mathrm{LD}_{50}$ values of $\mathrm{V}_{5} 83$ in different determinations were lower $\left(4.8 \times 10^{7}\right.$ to $1.1 \times 10^{8}$ colony forming units $(\mathrm{CFU}) / \mathrm{ml}$ ) than the $\mathrm{LD}_{50}$ values of OG1RF $\left(1.2 \times 10^{8}\right.$ to $\left.4.8 \times 10^{8} \mathrm{CFU} / \mathrm{ml}\right)$. However, at comparable inoculum, OG1RF $\left(4 \times 10^{8} \mathrm{CFU} / \mathrm{ml}\right)$ showed more rapid mortality versus $\mathrm{V}_{5} 83\left(5 \times 10^{8} \mathrm{CFU} / \mathrm{ml}\right)$ in the first 48 hours $(P=0.0034$; Additional data file 3$)$. In a urinary tract infection model administering mixed equal inocula of V583 and OG1RF, OG1RF significantly outnumbered V583 in kidney with geometric means of $1.3 \times 10^{4} \mathrm{CFU} / \mathrm{gm}$ for OG1RF versus $1.9 \times 10^{2} \mathrm{CFU} / \mathrm{gm}$ for $\mathrm{V}_{5} 83(P=0.0005)$; in urinary bladder homogenates, the geometric mean CFU/gm was $1.7 \times$ $10^{3}$ for OG1RF versus $6.6 \times 10^{1}$ for $\mathrm{V}_{5} 83(P=0.003$; Figure 7a). Similarly, in mono-infection, the geometric mean CFU/ gm of OG1RF in kidneys was $9.4 \times 10^{3}$ versus $4 \times 10^{1}$ for $\mathrm{V}_{5} 83$ $(P=0.0035$; Figure $7 \mathrm{~b})$. We also found that OG1RF produced 20\% more biofilm $(P<0.01)$ than $\mathrm{V}_{5} 83$ at 24 hours (results not shown). These results, together with the previous results in C. elegans [17], demonstrate that OG1RF, although lacking what was thought to be important for virulence (PAI, plasmids, prophages), is as pathogenic as $\mathrm{V}_{583}$ in at least three assays.

\section{Conclusion}

E. faecalis OG1RF carries a number of unique loci compared to V583. Those of particular interest include new surface proteins (MSCRAMMs and WxL domain proteins), an operon encoding myo-inositol utilization, an intact competence operon, and two CRISPR elements. The CRISPR elements may be of particular significance when one considers that most of what is missing from OG1RF compared to V583 consists of mobile genetic elements (MGEs), including 6 phages or remnants thereof. The presence of the CRISPR elements in OG1RF provides a tantalizing, but as yet unproven, explanation for the discordance in the number of mobile elements between these two strains.

The acquisition of MGE is believed to be an important mechanism by which the species $E$. faecalis had been able to generate genetic diversity and, thereby, highly variable phenotypes [4]. It has been proposed that the ability of E. faecalis to cause healthcare related infections is associated with these MGEs $[4,5]$. This hypothesis was supported by several studies that have highlighted the importance of virulence determinants carried by these mobile elements, such as cytolysin [57] by the PAI. However, more recent results from Aakra et al. [53] and Lepage et al. [36] demonstrate that these factors may be present in harmless strains while absent in clinical isolates, indicating that E. faecalis virulence is not dependent on any single virulence factor. Indeed, few studies have compared the virulence pattern of strains from various origins. The increased ability of OG1RF to infect kidneys and to produce biofilm, despite the absence of MGEs and their 
(a)

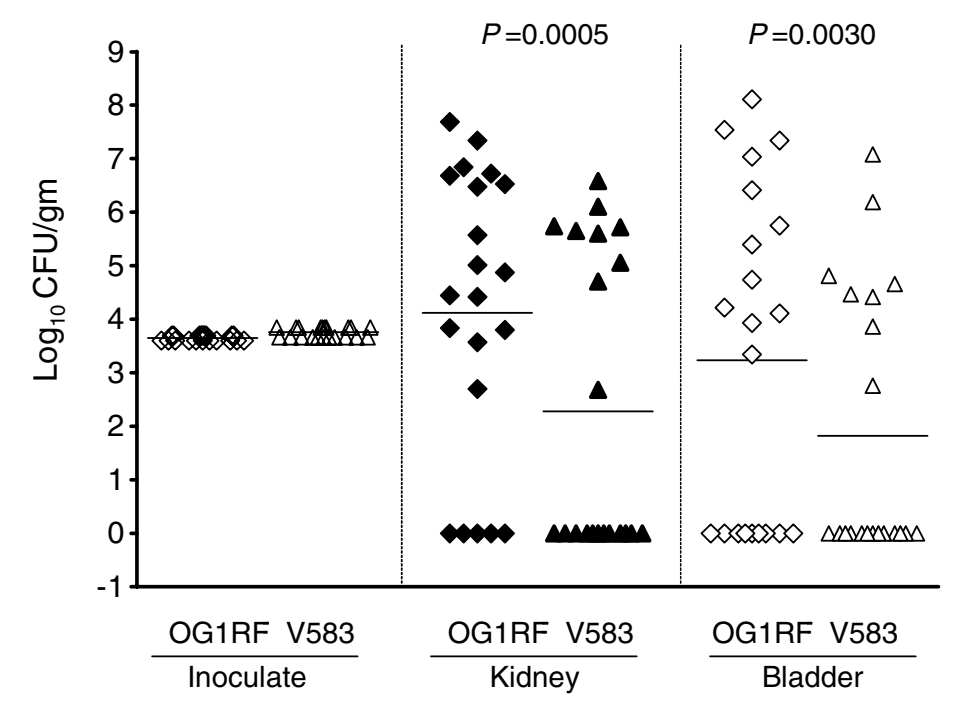

(b)

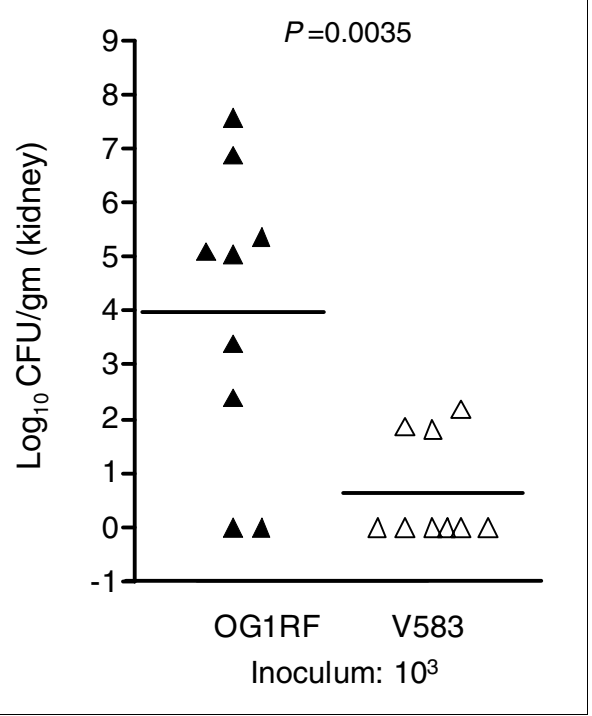

Figure 7

Comparison of OGIRF and V583 in a mouse urinary tract infection model. (a) Mixed infection by wild-type $E$. faecalis strains OGIRF and V583 in the kidneys and urinary bladders of mice $\left(n=21\right.$; competition assay). Data are expressed as the $\log _{10}(C F U) / g m$ for OGIRF or V583; the log 10 (CFU)/gm for both kidneys were combined and averaged from two independent experiments. Black solid diamonds and triangles represent $E$. faecalis strains $O G I R F$ and V583, respectively, for kidney homogenates, and empty diamonds and triangles represent OGIRF and V583, respectively, for urinary bladder homogenates. Horizontal bars represent geometric means. Log 10 (CFU) were compared for statistical significance by the paired $t$-test. The minimum detection limit in these experiments was $10^{1}$ and $10^{2} \mathrm{CFU} / \mathrm{gm}$ of kidney and urinary bladder homogenates, respectively. (b) Mono-infection using $E$. faecalis strains OGIRF or V583 in the kidneys of mice ( $10^{3} \mathrm{CFU}$ per mice, $\left.n=9\right)$. Data are expressed as $\log _{10}(\mathrm{CFU}) / \mathrm{gm}$ for OG IRF recovered from kidney homogenates $48 \mathrm{~h}$ after infection; the $\log _{10}(\mathrm{CFU}) / \mathrm{gm}$ for a kidney pair were combined and averaged. Black and white triangles represent $\mathrm{OGIRF}$ and V583, respectively. Horizontal bars represent geometric means. The CFU of V583 recovered from kidneys was significantly reduced compared to the CFU of OGIRF, as determined by the unpaired $t$-test.

associated virulence factors, was surprising. Different possibilities can be proposed relating to the factors important for these differences in enterococcal infections. One of these is that virulence in the assays used may be linked to the shared core genome of these two strains, with the differences arising from the unique genes. On the other hand, virulence could be associated primarily with the genes unique to each strain, but with each set being able to complement the absence of the other. It seems most likely that virulence, and/or some combination of virulence and fitness, is caused by the expression of a mixture of both the core and unique genes. It is also important to remember that $E$. faecalis is a well adapted commensal, carrying the genes necessary to survive and to colonize the gut, and that a subset, particularly MLST CC2 and CC9 [58], predominates among hospital acquired infections. It may be that these clonal complexes are not more virulent per se, as defined in the assays described here, but rather are better able to survive and/or colonize hospitalized patients, taking advantage of factors that predispose to nosocomial infections such as urinary or venous catheters, or mucositis, among others.
Sequencing of more E. faecalis strains may facilitate our understanding of the path from commensalism to pathogenicity, a crucial prerequisite for designing therapeutic interventions directed to control an organism that is already resistant to a large spectrum of antibiotics.

\section{Materials and methods Strains}

E. faecalis $\mathrm{OG} 1$ is a strain of human origin (formerly designated $2 \mathrm{SaR}[7]$ ) and was subsequently selected on rifampicin and fusidic acid $[8,9]$ to generate OG1RF (deposited at the American Type Culture Collection (ATCC) under ATCC accession number 47077). V583 is a vancomycin resistant $E$. faecalis strain [6], recovered from a blood culture of a patient hospitalized at the Barnes Hospital, St Louis, MO, USA in February 1987 (ATCC accession number 700802, NCBI complete genome accession number NC_oo4668). Bacteria were grown routinely at $37^{\circ} \mathrm{C}$ in $\mathrm{BHI}$ broth (Difco Laboratories, Detroit, MI, USA) or BHI agar unless otherwise indicated. Comparisons of OG1RF and V583 grown in broth (BHI, tryptic soy broth with glucose (TSBG), or BHI with 40\% serum) did not reveal any obvious differences. 


\section{DNA sequencing and genome assembly}

Genomic DNA was purified from cesium chloride $(\mathrm{CsCl})$ gradients of whole cell lysates [10]. DNA sequencing was performed by a combined approach using 454 Life Sciences pyrosequencing strategies [59] and the Solexa approach [6o]. Read-pair information was used to create higher order scaffolds. Sanger sequencing was used for OG1RF whole gun sequencing and finishing. The coverage was $28 \times$ by the 454 , $104 \times$ by Solexa, and $4.5^{\times}$by Sanger sequencing technique. The assembly was done using Atlas [61].

\section{Gene identification and annotation}

Gene prediction and manual annotation were performed as previously described [62]. Glimmer [63] and GeneMark [64] were used independently to predict ORFs. Visualization of gene predictions was performed using the Genboree system [65] and the CONAN database [66]. OG1RF-unique ORFs were analyzed with BLASTN and BLASTX. Protein sequences were analyzed by BLASTP versus the nr database at NCBI [67]. When appropriate, other predictive tools were used as described previously [62]. This whole genome shotgun project has been deposited at DDBJ/EMBL/GenBank under the project accession ABPIoooooooo. The version described in this paper is the first version, ABPIo1000000. This project includes also the annotation of the ORFs unique to OG1RF. The OG1RF-unique ORFs are listed in Additional data file 1.

\section{Transposon mutations in OG IRF-unique sequences}

Following the creation of an E. faecalis Tn917 library [12], 6,237 sequences representing the flanking regions of the transposon insertion sites were obtained and compared to the V583 genome by BLASTN. A total of 196 sequences were unique to OG1RF. Thirty-seven of the unique genes contained a transposon insertion. The locations of the transposon insertions are listed in Additional data file 1.

\section{Carbohydrate fermentation tests}

Forty-eight E. faecalis isolates, including OG1RF and V583, having different MLST profiles, pulsed field gel electrophoresis types or from various geographical origins, were streaked onto BHI agar and incubated overnight at $37^{\circ} \mathrm{C}$. Five to ten colonies of each strain were resuspended in $100 \mu$ of $0.9 \%$ saline in a microtiter plate and tested for fermentation using BBL $^{\mathrm{TM}}$ Phenol Red Broth Base (Diagnostic Systems, Sparks, MD, USA) supplemented with agar and either $10 \mathrm{mM}$ glucose (positive control), $10 \mathrm{mM}$ dulcitol (negative control), or 10 mM myo-inositol (Sigma, St Louis, MO, USA). Plates were read after incubation at $37^{\circ} \mathrm{C}$ for $24 \mathrm{~h}$; a yellow halo around the colony was considered positive for fermentation. iolB and iolG2 transposon mutants [12] were also tested.

\section{PCR}

PCR was performed using genomic DNA purified using Bactozol $^{\mathrm{TM}}$ (Molecular Research Center, Inc., Cincinnati, OH, USA), as recommended by the manufacturer. Specific PCR primer pairs (Additional data file 4) were used to assess the presence of the OG1RF-unique sequences and for confirmation of flanking DNA regions in common with $\mathrm{V}_{583}$.

\section{Competence assays}

To test strains for competence, overnight cultures, grown at $37^{\circ} \mathrm{C}$ in Todd-Hewitt broth, were diluted in Todd-Hewitt broth to an $\mathrm{OD}_{600 \mathrm{~nm}}$ of 0.05 and then further diluted 10,000fold in Todd-Hewitt broth to a final volume of $100 \mathrm{ml}$. After 30 minutes at $37^{\circ} \mathrm{C}$, with shaking at $150 \mathrm{rpm}$, and every hour for $10 \mathrm{~h}, 0.5 \mathrm{ml}$ samples were removed and $2.5 \mu \mathrm{g}$ of plasmid DNA were added. The plasmids tested were pAM401 [48] and pMSP3535VA [49]. The samples were incubated for $2 \mathrm{~h}$ before plating on BHI or BHI plus antibiotic (chloramphenical $10 \mu \mathrm{g} / \mathrm{ml}$ for pAM401 or kanamycin $2 \mathrm{mg} / \mathrm{ml}$ for pMSP3535VA). Following overnight incubation at $37^{\circ} \mathrm{C}$, the total numbers of $\mathrm{CFU} / \mathrm{ml}$ recovered on selective agar for the plasmid were compared to the total number of $\mathrm{CFU} / \mathrm{ml}$ (plated on BHI agar) for each time point.

\section{Biofilm assay and statistical analysis}

The biofilm assay was performed as described by Mohamed $e t$ al. [68]. Each assay was performed using 16 wells on three occasions. The median was calculated using the $48 \mathrm{OD}_{570 \mathrm{~nm}}$ readings on data pooled from all experiments and statistical analysis was performed using a non-parametric $t$-test.

\section{Mouse peritonitis model}

E. faecalis strains $\mathrm{OG}_{1 \mathrm{RF}}$ and $\mathrm{V}_{5} 83$ [6] were tested using a previously published method [13]. Mice were injected intraperitoneally with appropriate dilutions of premixed bacteria/ sterile rat fecal extract and were observed for five days. Twofold dilutions of test bacteria in the range 107-109 $\mathrm{CFU}$ were used as the inocula for $\mathrm{LD}_{50}$ determination using 6-9 mice per inoculum group. Inocula $\mathrm{CFU}$ geometric mean values were obtained and used for $\mathrm{LD}_{50}$ calculation by the method of Reed and Muench [69].

\section{UTI model for competition assay and ID50 determination}

E. faecalis strains $\mathrm{OG}_{1 \mathrm{RF}}$ and $\mathrm{V}_{5} 83$ were tested in the UTI model as previously described [16]. For the mixed inoculum experiments, an approximately $1: 1$ ratio of $E$. faecalis OG1RF:V583 at approximately $10^{3} \mathrm{CFU}$ each was used. Two independent experiments, using 10 and 11 mice, respectively, were performed and the results were combined. The $\log _{10}$ (CFU) of OG1RF and V583 per gram of tissue of each animal (kidney or bladder) from mixed infection were analyzed for significance by the paired $t$-test. For mono-infection, approximately $10^{3} \mathrm{CFU}$ organisms grown in $\mathrm{BHI}+40 \%$ horse serum were used for each strain independently and CFU obtained from kidney pairs (nine mice per strain) were analyzed for significance by the unpaired $t$-test. The minimum detectable limits of recovered bacteria were $10^{1}$ and $10^{2}$ $\mathrm{CFU} / \mathrm{gm}$ of kidney pairs and urinary bladder homogenates, respectively. 


\section{Abbreviations}

ATCC, American type culture collection; BHI, brain heart infusion; CC, clonal complex; $\mathrm{CFU}$, colony forming units; CRISPR, comprised of regularly interspaced short palindromic repeats; CSP, competence-stimulating peptide; HK-RR, histidine kinase-response regulator; MGE, mobile genetic element; MSCRAMM, microbial surface component recognizing adhesive matrix molecules; MLST, multilocus sequence typing; ORF, open reading frame; PAI, pathogenicity island.

\section{Authors' contributions}

GMW, DAG, and BEM designed the study. AB performed much of the post-annotation analysis and non-animal experiments, and wrote the draft of the manuscript. KVS performed the animal experiments. AB, DAG, XQ, JS, SY, AM, KAF, JG, CAA, YS, SRN, MZ, VPP, SC, and SKH annotated the genome. XQ and HJ contributed bioinformatics support. YD, SD-R, CB, HS, GC, GW, DM, LC, and RAG composed the sequencing and finishing team. DAG, BEM, SKH, and GMW assisted in critical review of the manuscript. All authors read and approved the final manuscript.

\section{Additional data files}

The following additional data files are available with the online version of this paper. Additional data file 1 is a list of the ORFs unique to OG1RF compared to V583 with their OG1RF locus tag, location in the genome, and definition. Additional data file 2 is a list of genes encoding proteins with a WxL domain in OG1RF and/or V583. Additional data file 3 shows the results of the mouse peritonitis model using $\mathrm{OG} 1 \mathrm{RF}$ and $\mathrm{V}_{5} 83$, with the statistical analysis. Additional data file 4 is a list of the significant primers used in this study.

\section{Acknowledgements}

We would like to express our sincere thanks to J Hernandez, S Wang, Z Li, D Ngo, and L Hemphill for their help during the sequencing process. We also would like to thank JM Urbach, Massachusetts General Hospital, Boston, MA for helping localize the transposon insertions in the OGIRF unique sequences. This research was supported by grant R2I Al064470 from the National Institutes of Health to GMW and by NIH grant R37 Al47923 from the Division of Microbiology and Infectious Diseases, NIAID, to BEM.

\section{References}

I. Murray BE: The life and times of the Enterococcus. Clin Microbiol Rev 1990, 3:46-65.

2. Willems RJ, Bonten MJ: Glycopeptide-resistant enterococci: deciphering virulence, resistance and epidemicity. Curr Opin Infect Dis 2007, 20:384-390.

3. Ogier JC, Serror P: Safety assessment of dairy microorganisms: The Enterococcus genus. Int J Food Microbiol 2007 in press.

4. Paulsen IT, Banerjei L, Myers GS, Nelson KE, Seshadri R, Read TD, Fouts DE, Eisen JA, Gill SR, Heidelberg JF, Tettelin H, Dodson RJ, Umayam L, Brinkac L, Beanan M, Daugherty S, DeBoy RT, Durkin S, Kolonay J, Madupu R, Nelson W, Vamathevan J, Tran B, Upton J, Hansen T, Shetty J, Khouri H, Utterback T, Radune D, Ketchum KA, et al: Role of mobile DNA in the evolution of vancomycinresistant Enterococcus faecalis. Science 2003, 299:207I-2074.
5. Domann E, Hain T, Ghai R, Billion A, Kuenne C, Zimmermann K, Chakraborty T: Comparative genomic analysis for the presence of potential enterococcal virulence factors in the probiotic Enterococcus faecalis strain Symbioflor I. Int J Med Microbiol 2007, 297:533-539.

6. Sahm DF, Kissinger J, Gilmore MS, Murray PR, Mulder R, Solliday J, Clarke B: In vitro susceptibility studies of vancomycin-resistant Enterococcus faecalis. Antimicrob Agents Chemother 1989, 33:1588-159|.

7. Gold OG, Jordan HV, van Houte J: The prevalence of enterococci in the human mouth and their pathogenicity in animal models. Arch Oral Biol 1975, 20:473-477.

8. Dunny GM, Brown BL, Clewell DB: Induced cell aggregation and mating in Streptococcus faecalis : evidence for a bacterial sex pheromone. Proc Natl Acad Sci USA 1978, 75:3479-3483.

9. Oliver DR, Brown BL, Clewell DB: Analysis of plasmid deoxyribonucleic acid in a cariogenic strain of Streptococcus faecalis : an approach to identifying genetic determinants on cryptic plasmids. J Bacteriol 1977, I 30:759-765.

10. Murray BE, Singh KV, Ross RP, Heath JD, Dunny GM, Weinstock GM: Generation of restriction map of Enterococcus faecalis OG I and investigation of growth requirements and regions encoding biosynthetic function. J Bacteriol 1993, 1 75:52 16-5223.

II. Nallapareddy SR, Wenxiang H, Weinstock GM, Murray BE: Molecular characterization of a widespread, pathogenic, and antibiotic resistance-receptive Enterococcus faecalis lineage and dissemination of its putative pathogenicity island. J Bacteriol 2005, I 87:5709-57|8.

12. Garsin DA, Urbach J, Huguet-Tapia JC, Peters JE, Ausubel FM: Construction of an Enterococcus faecalis Tn9 I 7-mediated-genedisruption library offers insight into Tn9/7 insertion patterns. J Bacteriol 2004, I 86:7280-7289.

13. Singh KV, Coque TM, Weinstock GM, Murray BE: In vivo testing of an Enterococcus faecalis efaA mutant and use of efaA homologs for species identification. FEMS Immunol Med Microbiol 1998, 2 1:323-331.

14. Mylonakis E, Engelbert M, Qin X, Sifri CD, Murray BE, Ausubel FM, Gilmore MS, Calderwood SB: The Enterococcus faecalis fsrB gene, a key component of the fsr quorum-sensing system, is associated with virulence in the rabbit endophthalmitis model. Infect Immun 2002, 70:4678-468I.

15. Singh KV, Nallapareddy SR, Nannini EC, Murray BE: Fsr-independent production of protease(s) may explain the lack of attenuation of an Enterococcus faecalis fsr mutant versus a gelEsprE mutant in induction of endocarditis. Infect Immun 2005, 73:4888-4894.

16. Singh KV, Nallapareddy SR, Murray BE: Importance of the ebp (Endocarditis- and Biofilm-Associated Pilus) locus in the pathogenesis of Enterococcus faecalis ascending urinary tract infection. J Infect Dis 2007, 195:167|-1677.

17. Garsin DA, Sifri CD, Mylonakis E, Qin X, Singh KV, Murray BE, Calderwood SB, Ausubel FM: A simple model host for identifying Gram-positive virulence factors. Proc Natl Acad Sci USA 2001, 98: 10892-10897.

18. Nallapareddy SR, Singh KV, Sillanpaa J, Garsin DA, Hook M, Erlandsen SL, Murray BE: Endocarditis and biofilm-associated pili of Enterococcus faecalis. J Clin Invest 2006, I I 6:2799-2807.

19. Bourgogne A, Singh KV, Fox KA, Pflughoeft KJ, Murray BE, Garsin DA: EbpR is important for biofilm formation by activating expression of the endocarditis and biofilm-associated pilus operon (ebpABC) of Enterococcus faecalis OGIRF. J Bacteriol 2007, 189:6490-6493.

20. Nallapareddy SR, Singh KV, Duh RW, Weinstock GM, Murray BE: Diversity of ace, a gene encoding a microbial surface component recognizing adhesive matrix molecules, from different strains of Enterococcus faecalis and evidence for production of ace during human infections. Infect Immun 2000, 68:5210-5217.

21. Nallapareddy SR, Murray BE: Ligand-signaled upregulation of Enterococcus faecalis ace transcription, a mechanism for modulating host-E. faecalis interaction. Infect Immun 2006, 74:4982-4989.

22. Bourgogne A, Hilsenbeck SG, Dunny GM, Murray BE: Comparison of OG IRF and an isogenic fsrB deletion mutant by transcriptional analysis: the Fsr system of Enterococcus faecalis is more than the activator of gelatinase and serine protease. J Bacteriol 2006, I 88:2875-2884.

23. Qin X, Singh KV, Weinstock GM, Murray BE: Effects of Enterococ- 
cus faecalis fsr genes on production of gelatinase and a serine protease and virulence. Infect Immun 2000, 68:2579-2586.

24. Sifri CD, Mylonakis E, Singh KV, Qin X, Garsin DA, Murray BE, Ausubel FM, Calderwood SB: Virulence effect of Enterococcus faecalis protease genes and the quorum-sensing locus $f s r$ in Caenorhabditis elegans and mice. Infect Immun 2002, 70:5647-5650.

25. Barrangou R, Fremaux C, Deveau H, Richards M, Boyaval P, Moineau $S$, Romero DA, Horvath P: CRISPR provides acquired resistance against viruses in prokaryotes. Science 2007, 3 I5:1709-17/2.

26. Horvath P, Romero DA, Coute-Monvoisin AC, Richards M, Deveau $\mathrm{H}$, Moineau S, Boyaval P, Fremaux C, Barrangou R: Diversity, activity, and evolution of CRISPR loci in Streptococcus thermophilus. J Bacteriol 2008, I 90: |40|-|4|2.

27. Deveau H, Barrangou R, Garneau JE, Labonte J, Fremaux C, Boyaval $P$, Romero DA, Horvath $P$, Moineau S: Phage response to CRISPR-encoded resistance in Streptococcus thermophilus. J Bacteriol 2008, I 90:1390-1400.

28. Haft DH, Selengut J, Mongodin EF, Nelson KE: A guild of 45 CRISPR-associated (Cas) protein families and multiple CRISPR/Cas subtypes exist in prokaryotic genomes. PLoS Comput Biol 2005, I:e60.

29. Nakayama J, Kariyama R, Kumon H: Description of a 23.9-kilobase chromosomal deletion containing a region encoding $\mathrm{fsr}$ genes which mainly determines the gelatinase-negative phenotype of clinical isolates of Enterococcus faecalis in urine. Appl Environ Microbiol 2002, 68:3।52-3। 55.

30. Roberts JC, Singh KV, Okhuysen PC, Murray BE: Molecular epidemiology of the fsr locus and of gelatinase production among different subsets of Enterococcus faecalis isolates. I Clin Microbiol 2004, 42:2317-2320.

31. McBride SM, Fischetti VA, Leblanc DJ, Moellering RC Jr, Gilmore MS: Genetic diversity among Enterococcus faecalis. PLOS ONE 2007, 2:e582.

32. Rich RL, Demeler B, Ashby K, Deivanayagam CC, Petrich JW, Patti JM, Narayana SV, Hook M: Domain structure of the Staphylococcus aureus collagen adhesin. Biochemistry 1998, 37: I5423-I5433.

33. Siezen R, Boekhorst J, Muscariello L, Molenaar D, Renckens B, Kleerebezem M: Lactobacillus plantarum gene clusters encoding putative cell-surface protein complexes for carbohydrate utilization are conserved in specific gram-positive bacteria. BMC Genomics 2006, 7:126.

34. Brinster S, Furlan S, Serror P: C-terminal $\mathbf{W} \mathbf{x L}$ domain mediates cell wall binding in Enterococcus faecalis and other gram-positive bacteria. J Bacteriol 2007, I 89: I 244- 253.

35. Brinster S, Posteraro B, Bierne H, Alberti A, Makhzami S, Sanguinetti $M$, Serror P: Enterococcal leucine-rich repeat-containing protein involved in virulence and host inflammatory response. Infect Immun 2007, 75:4463-447I.

36. Lepage E, Brinster S, Caron C, Ducroix-Crepy C, Rigottier-Gois L, Dunny G, Hennequet-Antier C, Serror P: Comparative genomic hybridization analysis of Enterococcus faecalis : identification of genes absent from food strains. I Bacteriol 2006, I 88:6858-6868.

37. Hufnagel M, Hancock LE, Koch S, Theilacker C, Gilmore MS, Huebner J: Serological and genetic diversity of capsular polysaccharides in Enterococcus faecalis. J Clin Microbiol 2004, 42:2548-2557.

38. Hancock $L$, Perego M: Two-component signal transduction in Enterococcus faecalis. J Bacteriol 2002, 184:58|9-5825.

39. Kelly JA, Knox JR, Moews PC, Hite GJ, Bartolone JB, Zhao H, Joris B, Frere JM, Ghuysen JM: 2.8-A Structure of penicillin-sensitive $D$ alanyl carboxypeptidase-transpeptidase from Streptomyces R6I and complexes with beta-lactams. J Biol Chem 1985, 260:6449-6458.

40. Sauvage E, Herman R, Petrella S, Duez C, Bouillenne F, Frere JM, Charlier P: Crystal structure of the Actinomadura R39 DDpeptidase reveals new domains in penicillin-binding proteins. J Biol Chem 2005, 280:3 I249-3I 256.

4I. Yoshida KI, Aoyama D, Ishio I, Shibayama T, Fujita Y: Organization and transcription of the myo-inositol operon,iol, of Bacillus subtilis. J Bacteriol 1997, 179:459|-4598.

42. Barr JG, Mahood RJ: An assessment of inositol fermentation by Klebsiellae and its implication in screening media. J Clin Pathol 1976, 29:827-832.

43. Paliwal DK, Randhawa HS, Kowshik T: A modified method for testing inositol assimilation by Cryptococcus species. Can J Microbiol 1979, 25: I I88-II90.

44. Kawsar HI, Ohtani K, Okumura K, Hayashi H, Shimizu T: Organiza- tion and transcriptional regulation of myo-inositol operon in Clostridium perfringens. FEMS Microbiol Lett 2004, 235:289-295.

45. Yebra MJ, Zuniga M, Beaufils S, Perez-Martinez G, Deutscher J, Monedero $\mathrm{V}$ : Identification of a gene cluster enabling Lactobacillus casei BL23 to utilize myo-inositol. Appl Environ Microbiol 2007, 73:3850-3858.

46. Rice LB, Carias LL, Marshall SH, Hutton-Thomas R, Rudin S: Characterization of Tn5386, a Tn916-related mobile element. Plasmid 2007, 58:6I-67.

47. Merritt J, Qi F, Shi W: A unique nine-gene comY operon in Streptococcus mutans. Microbiology 2005, 15 I:157-166.

48. Wirth R, An FY, Clewell DB: Highly efficient protoplast transformation system for Streptococcus faecalis and a new Escherichia coli-S. faecalis shuttle vector. J Bacteriol 1986, 165:83|-836.

49. Bryan EM, Bae T, Kleerebezem M, Dunny GM: Improved vectors for nisin-controlled expression in gram-positive bacteria. Plasmid 2000, 44: I83-190.

50. Alloing G, Martin B, Granadel C, Claverys JP: Development of competence in Streptococcus pneumoniae : pheromone autoinduction and control of quorum sensing by the oligopeptide permease. Mol Microbiol 1998, 29:75-83.

51. Martin B, Prudhomme M, Alloing G, Granadel C, Claverys JP: Crossregulation of competence pheromone production and export in the early control of transformation in Streptococcus pneumoniae. Mol Microbiol 2000, 38:867-878.

52. Petersen FC, Scheie AA: Genetic transformation in Streptococcus mutans requires a peptide secretion-like apparatus. Oral Microbiol Immunol 2000, 15:329-334.

53. Aakra A, Nyquist OL, Snipen L, Reiersen TS, Nes IF: Survey of genomic diversity among Enterococcus faecalis strains by microarray-based comparative genomic hybridization. Appl Environ Microbiol 2007, 73:2207-2217.

54. Ozawa Y, De Boever EH, Clewell DB: Enterococcus faecalis sex pheromone plasmid pAM373: analyses of TraA and evidence for its interaction with RpoB. Plasmid 2005, 54:57-69.

55. O'Neill A, Oliva B, Storey C, Hoyle A, Fishwick C, Chopra I: RNA polymerase inhibitors with activity against rifampin-resistant mutants of Staphylococcus aureus. Antimicrob Agents Chemother 2000, 44:3163-3166.

56. Nagaev I, Bjorkman J, Andersson DI, Hughes D: Biological cost and compensatory evolution in fusidic acid-resistant Staphylococcus aureus. Mol Microbiol 200I, 40:433-439.

57. Cox CR, Coburn PS, Gilmore MS: Enterococcal cytolysin: a novel two component peptide system that serves as a bacterial defense against eukaryotic and prokaryotic cells. Curr Protein Pept Sci 2005, 6:77-84.

58. Leavis HL, Bonten MJ, Willems RJ: Identification of high-risk enterococcal clonal complexes: global dispersion and antibiotic resistance. Curr Opin Microbiol 2006, 9:454-460.

59. Margulies M, Egholm M, Altman WE, Attiya S, Bader JS, Bemben LA Berka J, Braverman MS, Chen YJ, Chen Z, Dewell SB, Du L, Fierro JM, Gomes XV, Godwin BC, He W, Helgesen S, Ho CH, Irzyk GP, Jando SC, Alenquer ML, Jarvie TP, Jirage KB, Kim JB, Knight JR, Lanza JR, Leamon JH, Lefkowitz SM, Lei M, Li J, et al.: Genome sequencing in microfabricated high-density picolitre reactors. Nature 2005, 437:376-380

60. Bennett S: Solexa Ltd. Pharmacogenomics 2004, 5:433-438.

6I. Havlak P, Chen R, Durbin KJ, Egan A, Ren Y, Song XZ, Weinstock GM, Gibbs RA: The Atlas genome assembly system. Genome Res 2004, 14:721-732.

62. Gioia J, Yerrapragada S, Qin X, Jiang H, Igboeli OC, Muzny D, DuganRocha S, Ding Y, Hawes A, Liu W, Perez L, Kovar C, Dinh H, Lee S, Nazareth L, Blyth P, Holder M, Buhay C, Tirumalai MR, Liu Y, Dasgupta I, Bokhetache L, Fujita M, Karouia F, Eswara Moorthy P, Siefert J, Uzman A, Buzumbo P, Verma A, Zwiya H, et al.: Paradoxical DNA repair and peroxide resistance gene conservation in Bacillus pumilus SAFR-032. PLoS ONE 2007, 2:e928.

63. Delcher AL, Harmon D, Kasif S, White O, Salzberg SL: Improved microbial gene identification with GLIMMER. Nucleic Acids Res 1999, 27:4636-4641.

64. Lukashin AV, Borodovsky M: GeneMark.hmm: new solutions for gene finding. Nucleic Acids Res 1998, 26: I I07-I I I5.

65. Genboree [http://www.genboree.org/java-bin/login.jsp]

66. McLeod MP, Qin X, Karpathy SE, Gioia J. Highlander SK, Fox GE, McNeill TZ, Jiang H, Muzny D, Jacob LS, Hawes AC, Sodergren E, Gill R, Hume J, Morgan M, Fan G, Amin AG, Gibbs RA, Hong C, Yu XJ, Walker $\mathrm{DH}$, Weinstock GM: Complete genome sequence of 
Rickettsia typhi and comparison with sequences of other rickettsiae. J Bacteriol 2004, 186:5842-5855.

67. Wheeler DL, Barrett T, Benson DA, Bryant SH, Canese K, Church DM, DiCuccio M, Edgar R, Federhen S, Helmberg W, Kenton DL, Khovayko O, Lipman DJ, Madden TL, Maglott DR, Ostell J, Pontius JU, Pruitt KD, Schuler GD, Schriml LM, Sequeira E, Sherry ST, Sirotkin K, Starchenko G, Suzek TO, Tatusov R, Tatusova TA, Wagner L, Yaschenko E: Database resources of the National Center for Biotechnology Information. Nucleic Acids Res 2005, 33:D39-D45.

68. Mohamed JA, Huang W, Nallapareddy SR, Teng F, Murray BE: Influence of origin of isolates, especially endocarditis isolates, and various genes on biofilm formation by Enterococcus faecalis. Infect Immun 2004, 72:3658-3663.

69. Reed L, Muench $\mathrm{H}$ : A simple method of estimating fifty per cent end points. Am J Hygiene 1938, 27:493-497.

70. TIGR [http://www.tigr.org/] 